\title{
1 Dynamic aspects of plant water potential revealed by a microtensiometer
}

2 Vinay Pagay ${ }^{1^{*}}$

$3 \quad{ }^{1}$ School of Agriculture, Food \& Wine, Waite Research Institute, The University of Adelaide, PMB 1,

4 Glen Osmond, SA 5064, Australia

* Correspondence: vinay.pagay@adelaide.edu.au

\section{Abstract}

7 Water potential is a fundamental thermodynamic parameter that describes the activity of water. In 8 this paper, we describe the continuous measurement of plant water potential, a reliable indicator of 9 its water status, using a novel in situ sensor known as a 'microtensiometer' in mature grapevines under field conditions. The microtensiometer operates on the principle of equilibration of water potentials of internal liquid water with an external vapour or liquid phase. We characterised the seasonal and diurnal dynamics of trunk water potentials ( $\Psi_{\text {trunk }}$ ) obtained from microtensiometers installed in two grapevine cultivars, Shiraz and Cabernet Sauvignon, and compared these values to pressure chamberderived stem $\left(\Psi_{\text {stem }}\right)$ and leaf $\left(\Psi_{\text {leaf }}\right)$ water potentials as well as leaf stomatal conductance. Diurnal patterns of $\Psi_{\text {trunk }}$ matched those of $\Psi_{\text {stem }}$ and $\Psi_{\text {leaf }}$ under low vapour pressure deficit (VPD) conditions, but diverged under high VPD conditions. The highest diurnal values of $\Psi_{\text {trunk }}$ were observed shortly after dawn, while the lowest values were typically observed in the late afternoon. Differential responses of $\Psi_{\text {trunk }}$ to VPD were observed between cultivars, with Shiraz more sensitive than Cabernet to increasing VPD over long time scales, and both cultivars had a stronger VPD response than soil moisture response. On a diurnal basis, however, time cross correlation analysis revealed that Shiraz $\Psi_{\text {trunk }}$ lagged Cabernet $\Psi_{\text {trunk }}$ in response to changing VPD. Microtensiometers were shown to operate reliably under field conditions over several months. To be useful for irrigation scheduling of woody crops, new thresholds of $\Psi_{\text {trunk }}$ need to be developed.

Keywords: water potential, microtensiometer, soil moisture, irrigation, stomatal conductance, 


\section{Introduction}

Measurements of crop water status, which are essential for optimised irrigation scheduling, have historically relied on low throughput and high cost instruments, and labour intensive methods, that have decreased their utility and uptake by the farming community. One such method widely established to reliably quantify plant water status is the manual measurement of leaf or stem water potential (Shackel, 2011; Williams and Baeza, 2007), using a Scholander pressure chamber invented in the 1960s (Scholander et al., 1965). To overcome some of the limitations of such manual techniques, several electronic plant-based sensors to continuously measure crop water status have recently been developed that are based on various sensing modalities. These include sap flow sensors (Ginestar et al., 1998), thermal diffusivity sensors (Pagay and Skinner, 2018), dendrometers (Corell et al., 2014), and thermal or infrared sensors (Jones, 1999). A recent review of several of these sensors as applied in tree fruit crops can be found in Scalisi et al. (2017).

Given the prevalence of water potential as a reliable crop water status metric, sensors to measure plant water potential have also been developed. These sensors, known as hygrometers or psychrometers, provide continuous measurements of water potential either as contact sensors on leaves or in situ sensors embedded in stems (Dixon and Tyree, 1984; McBurney and Costigan, 1984; Michel, 1977). Hygrometers measure the water potential of the vapour phase. They are prone to significant errors due to the requirement of isothermal conditions between the measurement junction and plant tissue (Dixon and Tyree, 1984). A $1^{\circ} \mathrm{K}$ temperature difference between the plant tissue and sensor can result in a water potential error of over 7.7 MPa (Dixon and Tyree, 1984). Much like stem hygrometers, other in situ sensors embedded in the stems or trunks include those that measure the osmotic potential of the xylem tissue and calibrated to stem water potential (Meron et al., 2015). The osmotic potential sensor requires proper fluidic contact between the sensor and the plant tissue, as well has long transients (order hours) associated with the measurement.

Tensiometers measure the water potential of an external matrix by equilibrating an internal, constant volume of water whose hydrostatic pressure is taken as the negative of the external water potential. Tensiometers were originally developed for measurement of soil matric potential (Richards, 1942) and have been used for irrigation scheduling of crops (Cormier et al., 2020). Based on this principle, Pagay et al. (2014) developed MEMS-based tensiometers, so-called 'microtensiometers' (MT), for rapid measurements of the water potential of an external matrix. The MTs were previously shown to operate reliably down to below -10 MPa with short transients (equilibration or response times) of $20 \mathrm{~min}$. This measurement range and temporal resolution makes the sensors valuable for not only crop and soil water status monitoring, but also other contexts including meteorology, concrete curing and food processing, and other systems where the internal water status is required. Subsequent improvements on the original MT design for improved transients (faster response times) were made by Black et al. (2020). This second generation microtensiometer was used for both in situ and ex situ measurements of water potential in a range of matrices including foods.

This paper presents the first results of field experiments with MTs, embedded water potential sensors, in mature grapevines grown under different environmental and soil moisture conditions in a Mediterranean climate. We compared the dynamic MT responses of plant water potential to values of leaf and stem water potentials as measured by the Scholander pressure chamber over both long term and short term (diurnal) periods, and with other environmental metrics including soil moisture and atmospheric conditions. Our goal was to validate the use of MTs in a field context and to provide new insights into the dynamics of plant water potential. 


\section{Materials and Methods}

\section{Experimental site and plant material}

Two commercial vineyard blocks located in the Coonawarra region of South Australia $\left(37.29^{\circ} \mathrm{S}\right.$, $140.83^{\circ} \mathrm{E}$ ) were selected for the trial. One block was planted in 1988 to Vitis vinifera cv. Cabernet Sauvignon grafted onto Schwarzmann rootstock, while the second block was planted in 2013 to $V$. vinifera $\mathrm{cv}$. Shiraz (syn. Syrah) grafted onto Teleki $5 \mathrm{C}$ rootstock. Both vineyards were situated within 5 $\mathrm{km}$ of each other and planted over the dominant 'terrarossa' soil, characterised by a distinctive redbrown, thick, clay B horizon soils overlying limestone, the depth to which is variable. In each vineyard, three adjacent vines per cultivar were selected for measurements, and, additionally, the middle vine for continuous monitoring of soil and plant water status (see details below). Vineyard management, irrigation, and integrated pest management were applied to both blocks as per convention in the region for premium winegrape production.

\section{Environmental monitoring and climatic conditions}

Environmental (weather) data for the vineyard blocks was obtained from the Coonawarra weather station maintained by the Australian Bureau of Meteorology (BOM), Station ID: 026091. Daily maximum air vapour pressure deficit (VPD) was calculated using maximum temperature and minimum relative humidity $(\mathrm{RH})$ daily data. The long-term (20-year) mean January temperature (MJT) for Coonawarra is $19.3^{\circ} \mathrm{C}$ and the growing degree days (GDD; base $10{ }^{\circ} \mathrm{C}$; October-April) is 1511 . The climate of the area is characterised as Mediterranean, with winter dominant rainfall and relative summer drought. Average annual rainfall for Coonawarra is approx. $569 \mathrm{~mm}$ (Bureau_of_Meteorology, 2021). Supplemental irrigation is typically required from December until March. The elevation of the region is between $57 \mathrm{~m}$ and $63 \mathrm{~m}$ above sea level.

\section{Soil moisture measurements}

Of the three sentinel adjacent vines in each cultivar/block, the middle vine was selected for continuous monitoring of soil moisture, temperature and electrical conductivity using a capacitance-based sensor (Model: Teros-12, Meter Group, Pullman, WA, USA) buried approx. $30 \mathrm{~cm}$ below the surface and approx. $10 \mathrm{~cm}$ from the trunk of the vine in the vine row. The hourly sensor data was wirelessly transmitted via telemetry to a Cloud-based server and visually displayed on a user interface (Greenbrain, Measurement Engineering Australia, Adelaide, SA, Australia).

\section{Plant water status measurements}

\section{Leaf stomatal conductance}

In each block, leaf stomatal conductance $\left(g_{s}\right)$ was measured on the three sentinel vines per cultivar between $1200-1300 \mathrm{~h}$. Measurements were performed on one fully-expanded, healthy leaf per vine using an open system infrared gas analyser (IRGA; LI-6400XT, LI-COR Biosciences Inc., Lincoln, NE, USA) with a $6 \mathrm{~cm}^{2}$ cuvette. An external LED light source (LI-6400-02B) attached to the cuvette was used at a fixed PAR value of $1500 \mu \mathrm{mol} \mathrm{m} \mathrm{m}^{-2} \mathrm{~s}^{-1}$ due to the sometimes variable ambient light levels. The cuvette gas flow rate was set at $400 \mu \mathrm{mol} \mathrm{s}{ }^{-1}$ and reference $\mathrm{CO}_{2}$ was set to $400 \mathrm{ppm}$. The cuvette and leaf temperatures were at ambient (uncontrolled), while cuvette relative humidity with the leaf inserted was maintained within a range of 35-55\%. After IRGA measurements were performed, the same leaf was excised to determine leaf water potential (see below). IRGA measurements were conducted 
diurnally (every $2 \mathrm{~h}$ between 0800 and $2000 \mathrm{~h}$ ) on two days of contrasting VPDs - high VPD (February 17,2021 ) and low VPD (January 26, 2021) - that were typical of a Mediterranean region.

\section{Leaf and stem water potentials}

In each block, midday stem $\left(\Psi_{\text {stem }}\right)$ and leaf water potentials $\left(\Psi_{\text {leaf }}\right)$ were measured on adjacent mature leaves of the same shoot between the hours of 1200-1300 using a Scholander pressure chamber (Soil Moisture Equipment Corp., Santa Barbera, CA, USA). For $\Psi_{\text {stem }}$ measurements, leaves were bagged using an opaque aluminium-lined bag for a minimum of one hour prior to measurement to stop transpiration and allow for equilibration of water potentials between the leaf and shoot (stem). Measures of $\Psi_{\text {leaf }}$ and $\Psi_{\text {stem }}$ were performed on one leaf per vine from the three sentinel vines in each block/cultivar. Leaf and stem water potentials were measured diurnally on the two measurement days concurrently with IRGA measurements. The same leaf used for $g_{s}$ measurement with the IRGA was used to measure $\Psi_{\text {leaf }}$.

\section{Trunk water potentials}

On December 12, 2020, a total of four microtensiometers (MT; FloraPulse, Davis, CA, USA) were embedded into the trunks of the grapevines, two MTs per vine per cultivar. Readers are referred to Pagay et al. (2014) for a detailed description of the theory of tensiometry, and to Black et al. (2020) for technical details of the MT sensor design, fabrication, calibration, and lab testing results (performance under controlled conditions). Briefly, the MT consists of a micromachined piezoelectric pressure sensor coupled to a nanoporous silicon membrane via a cavity of liquid water. The membrane couples the external environment with the internal sensor water, allowing for the equilibration of water potentials. Decreases in the external water potential, i.e. below saturation vapour pressure, results in decreases in the hydrostatic pressure of the internal water $\left(P_{\text {liq }}\right)$, as the liquid phase water comes under tension or is stretched $\left(P_{\text {liq }}<0.1 \mathrm{MPa}\right)$. This relationship is shown in Eqn. 1 below.

$$
\Psi_{w}=\frac{R T}{v_{w}} \ln \left(p / p_{s a t}(T)\right)
$$

where, $\Psi_{\mathrm{w}}$ is the water potential $\left(=P_{\text {liq }}-P_{\text {atm }}\right), R$ is the ideal gas constant $\left(8.314 \mathrm{~J} \mathrm{~mol}^{-1} \mathrm{~K}^{-1}\right), v_{w}$ is the molar volume of water $\left(1.8 \times 10^{-5} \mathrm{~m}^{3} \mathrm{~mol}^{-1}\right), p$ is the partial pressure of vapour, and $p_{\text {sat }}$ is the saturation vapour pressure at temperature, $T$. The ratio of $p / p_{\text {sat }}$ is the relative humidity of the sample.

Two MTs (Fig. 1a) were embedded into each trunk of a woody, mature grapevine per cultivar. Sensor installation consisted of the following steps: (1) removal of bark on a flat section of the trunk; (2) removal of phloem tissue using a cork borer and spatula/blade; (3) insertion of a custom stainless steel sleeve (Fig. 1b; OD: $14 \mathrm{~mm}$, ID: $9 \mathrm{~mm}$ ) using a hammer; (4) Drilling into the sleeve approx. $5 \mathrm{~cm}$ into the trunk (within xylem tissue) and removing tissue; (5) filling the cavity with a kaolin-based mating compound; (6) inserting the hydrated MT into the mating compound; (7) placing a stainless steel cap to close the sleeve; (8) Covering the sleeve exterior at the trunk with silicone to ensure air and water proofing; (9) wrapping plastic film around the sensor followed by a $25 \mathrm{~mm}$ thick foam batting with reflective aluminium film to minimise exterior temperature fluctuations to the sensors (Fig. 1c). The sensors equilibrated with the vine (through the mating compound) within two days of installation. The MT data of trunk water potential ( $\Psi_{\text {trunk; }}$ v value averaged for both sensors), was obtained every $20 \mathrm{~min}$ wirelessly transmitted via telemetry to a Cloud-based server (Amazon Web Services, USA) and visually displayed on a user interface (FloraPulse, Davis, CA, USA). 


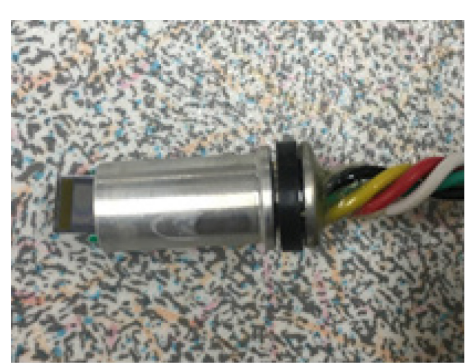

(a)

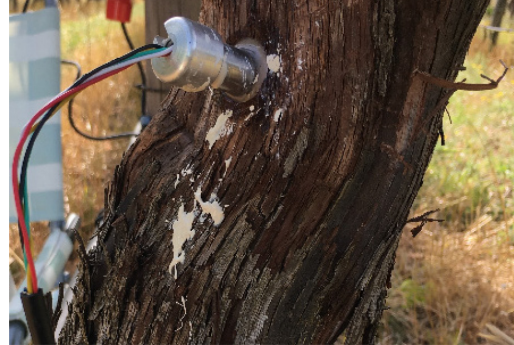

(b)

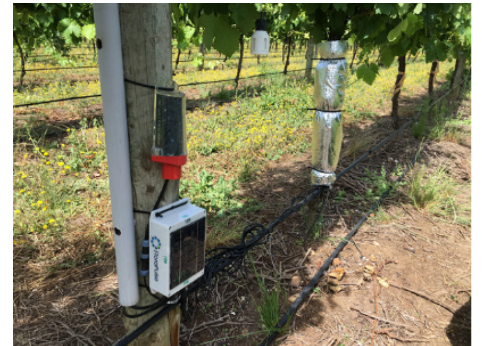

(c)

Figure 1: (a) Close up view of an individual microtensiometer showing the stainless steel packaging surrounding a protruding sensor chip. The tip of the chip consists of the nanoporous silicon membrane that allows for equilibration of water potentials between the exterior matrix and internal water; (b) MTs installed in a grapevine trunk within a stainless steel sleeve filled with kaolin mating compound; (c) Background: MT batting and reflective film to minimise temperature effects on water potential measurements of the sensor; Foreground: dataloggers and wireless transmitters of the MT (bottom unit, white box) and soil moisture sensor (top unit, red base).

\section{Statistical analyses}

Time-lagged cross correlation (TLCC) analysis was used in MATLAB programing software (v.9.8.0, R2020a, The MathWorks, Inc., Natick, MA, USA) to analyse the continuous (20-min interval) data of VPD and $\Psi_{\text {trunk }}$ over the course of two days with contrasting VPDs: January 26, 2021 (low VPD day; daily max. VPD 1.6 kPa) and January 24, 2021 (high VPD day; daily max. VPD 6.7 kPa). TLCC analysis involves determining the correlations between two time series datasets that are shifted in time (Chatfield and Xing, 2019), and repeatedly calculating Pearson Product Moment Correlation (cross correlation) Coefficient (XCC) after each shift (Cheong, 2020). Resulting 'offset' values, which when selected at the highest normalised XCC in the series, indicate the time shift (lag or advancement) of a particular time series compared to the other. Time shifts were selected such that they aligned with the VPD and $\Psi_{\text {trunk }}$ measurement interval of $20 \mathrm{~min}$, therefore each offset represented $20 \mathrm{~min}$.

\section{Results}

\section{Environmental conditions and soil moisture}

Measurements of environmental conditions and vine water status were made over the course of two days, one with high vapour pressure deficit (VPD) and the other with low VPD, during the 2020-21 growing season from 0800-2000 h. The low VPD day, January 26, 2021, was characterised by sunny and cool conditions, with the daily maximum temperature reaching just over $23^{\circ} \mathrm{C}$ with a maximum VPD of $1.7 \mathrm{kPa}$ at around $1400 \mathrm{~h}$ (Fig. $2 \mathrm{a}, \mathrm{g}$ ). This VPD was maintained until around $1600 \mathrm{~h}$ after which a decrease in solar radiation and temperature resulted in a decrease. Photosynthetically active radiation (PAR) was highest earlier in the day, around $1100 \mathrm{~h}$, and declining gradually after this time. On the high VPD day, February 17,2021 , maximum daily temperature was nearly $37^{\circ} \mathrm{C}$ and maximum VPD was approx. $6.0 \mathrm{kPa}$ (Fig. $2 \mathrm{~d}, \mathrm{j}$ ). This maximum VPD was reached around $1600 \mathrm{~h}$ and two hours later than the maximum PAR was reached. The maximum VPD on the high VPD day was reached two hours later than the maximum on the low VPD day. The high VPD day was also characterised by both warm mornings and evenings; VPD values exceeded $2 \mathrm{kPa}$, which was higher than the day-time maximum of the low VPD day.

Soil moisture measured using an in situ capacitance sensors placed approx. $30 \mathrm{~cm}$ below the surface and adjacent to the vine trunks indicated that the average volumetric water content (VWC) on the two measurement days were $24.0 \%$ and $30.6 \%$ on January 26 and February 17, respectively, in Shiraz; 
in Cabernet Sauvignon the VWC values were $28.3 \%$ and $30.3 \%$ on January 26 and February 17, respectively.

\section{Diurnal patterns of vine water status}

Patterns of leaf $\left(\Psi_{\text {leaf }}\right)$, stem $\left(\Psi_{\text {stem }}\right)$, and trunk $\left(\Psi_{\text {trunk }}\right)$ water potentials of the same vines were quantified over the course of the two measurements days under low and high VPD conditions for both Shiraz and Cabernet Sauvignon grapevines (Fig. 2b,e,h,k). A general pattern was observed in all the vines of a gradual decrease in water potential $\left(\Psi_{w}\right)$ over the course of the day, reaching a minimum in the mid-afternoon, followed by an increase in the evening. The water potentials observed across all dates and cultivars ranged between -0.3 MPa and -1.0 MPa for $\Psi_{\text {trunk, }}$, between $-0.1 \mathrm{MPa}$ and -0.95 $\mathrm{MPa}$ for $\Psi_{\text {stem, }}$, and -0.25 and $-1.5 \mathrm{MPa}$ for $\Psi_{\text {leaf }}$. The lowest $\Psi_{\mathrm{w}}$ values were generally observed around $1400 \mathrm{~h}$ each day, after which the values increased gradually.

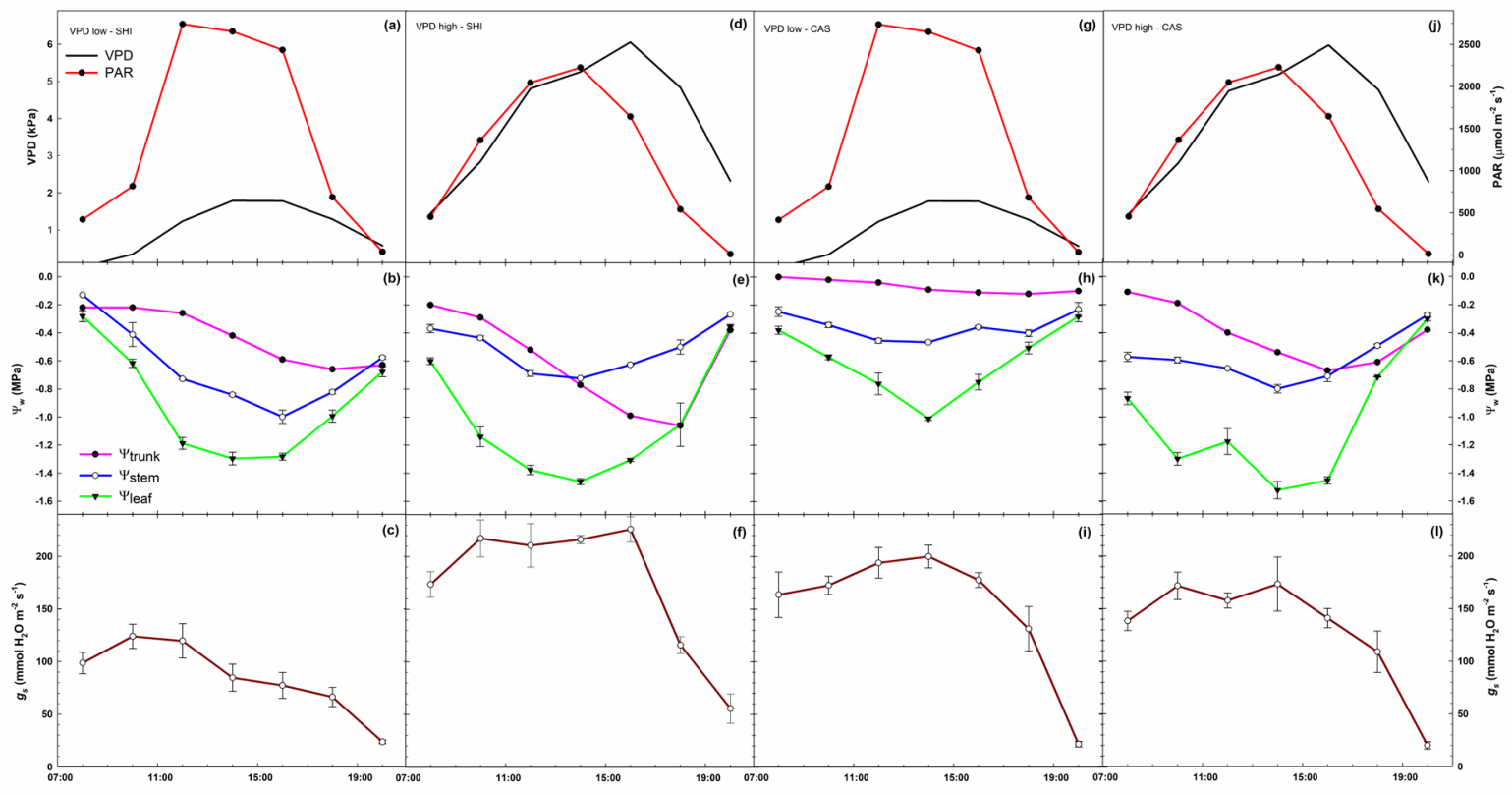

Figure 2: Diurnal patterns of VPD, PAR, trunk $\left(\Psi_{\text {trunk }}\right)$, stem $\left(\Psi_{\text {stem }}\right)$, leaf ( $\left.\Psi_{\text {leaf }}\right)$ water potentials, and leaf stomatal conductance $\left(g_{s}\right)$ on low and high VPD days for Shiraz (SHI) and Cabernet Sauvignon (CAS) grapevines.

Under low VPD $(\sim 1.7 \mathrm{kPa})$ conditions, Shiraz grapevines had $\Psi_{\text {trunk, }}, \Psi_{\text {stem, }}$, and $\Psi_{\text {leaf }}$ daily average minimum values of $-0.66,-0.96$, and $-1.30 \mathrm{MPa}$, respectively (Fig. 2b). Although the three $\Psi_{\mathrm{w}}$ values were similar in the early morning $(0800 \mathrm{~h})$ and late evening $(2000 \mathrm{~h})$, they reached maximum separation between $1200 \mathrm{~h}$ and $1400 \mathrm{~h}$, during which time the difference between them were approx. $0.3,0.3$, and $0.6 \mathrm{MPa}$ for $\Delta \Psi_{\text {trunk-stem, }} \Delta \Psi_{\text {stem-leaf }}$ and $\Delta \Psi_{\text {trunk-leaf, }}$, respectively. In comparison, Cabernet Sauvignon on the same day, i.e. under low VPD conditions, had $\Psi_{\text {trunk }}, \Psi_{\text {stem, }}$ and $\Psi_{\text {leaf }}$ daily average minimum values of $-0.12,-0.45$ and $-1.01 \mathrm{MPa}$, respectively (Fig. $2 \mathrm{~h}$ ), which were higher than the values observed in Shiraz for all three metrics. Similar (but not identical) to Shiraz, the differences between $\Psi_{\mathrm{w}}$ values were greatest around $1400 \mathrm{~h}$; difference values were approx. $0.3,0.3$ and $0.9 \mathrm{MPa}$ for $\Delta \Psi_{\text {trunk-stem, }} \Delta \Psi_{\text {stem-leaf }}$ and $\Delta \Psi_{\text {trunk-leaf, }}$ respectively. The diurnal patterns of $\Psi_{\mathrm{w}}$ were somewhat different compared to Shiraz; Cabernet did not drop its $\Psi_{\text {trunk }}$ and $\Psi_{\text {stem }}$ as much as Shiraz under the same conditions despite its $\Psi_{\text {leaf }}$ dropping to slightly below -1 MPa.

Under high VPD ( $6 \mathrm{kPa}$ ) conditions, Shiraz grapevines dropped their $\Psi_{\text {trunk, }}, \Psi_{\text {stem }}$ and $\Psi_{\text {leaf }}$ values to $1.1,-0.7,-1.5 \mathrm{MPa}$, respectively (Fig. 2e), which were considerably lower than during the low VPD day. 
Under these high VPD conditions in both cultivars, patterns of $\Psi_{w}$ early in the day were similar to the patterns observed during the low VPD day; the values of $\Psi_{\mathrm{w}}$ followed the expected order of $\Psi_{\text {trunk }}>$ $\Psi_{\text {stem }}>\Psi_{\text {leaf }}$ during the morning. However, a distinct shift in the pattern of $\Psi_{\text {trunk }}$ was observed after

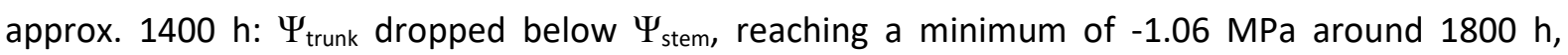
matching values observed for $\Psi_{\text {leaf. }}$ In comparison, $\Psi_{\text {stem }}$ at the same time $(1800 \mathrm{~h})$ was $-0.47 \mathrm{MPa}$. There was a noticeable recovery (increase) in $\Psi_{\text {trunk }}$ that started soon after $1800 \mathrm{~h}$, matching the values of $\Psi_{\text {leaf }}$ during this period late in the day $(1800 \mathrm{~h}-2000 \mathrm{~h})$. Under the same (high VPD) conditions, patterns of Cabernet Sauvignon $\Psi_{\mathrm{w}}$ were similar to that of Shiraz. Cabernet had large differences between $\Psi_{\text {trunk, }} \Psi_{\text {stem }}$ and $\Psi_{\text {leaf }}$ early in the day, and these reached their minimum values of -0.67, 0.76, and -1.5 MPa, respectively, between $1400-1600 \mathrm{~h}$ (Fig. 2k). Much like Shiraz under similar (high VPD) conditions, there was a distinct crossing-over of $\Psi_{\text {trunk }}$ and $\Psi_{\text {stem }}$ around $1600 \mathrm{~h} ; \Psi_{\text {trunk }}$ dropped

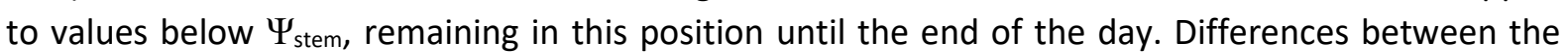
various metrics of $\Psi_{w}$ were more significant in Cabernet than in Shiraz; maximum difference values in Cabernet were approx. 0.1, 0.8 and 0.9 MPa for $\Delta \Psi_{\text {trunk-stem, }} \Delta \Psi_{\text {stem-leaf }}$ and $\Delta \Psi_{\text {trunk-leaf }}$, respectively, while in Shiraz the corresponding differences were $0.05,0.7$, and $0.7 \mathrm{MPa}$, respectively.

Leaf stomatal conductance $\left(g_{s}\right)$ was measured concurrently with $\Psi_{\mathrm{w}}$ measurements, and on the same leaf used to measure $\Psi_{\text {leaf. }}$ Patterns of $g_{s}$ mirrored $\Psi_{w}$ in both cultivars and across both measurement days under contrasting environmental conditions. In Shiraz, average $g_{s}$ values were highest early in the day, peaking around $124 \mathrm{mmol} \mathrm{H}_{2} \mathrm{O} \mathrm{m}^{-2} \mathrm{~s}^{-1}$ at $1000 \mathrm{~h}$ under low VPD conditions, and considerably higher around $235 \mathrm{mmol} \mathrm{H}_{2} \mathrm{O} \mathrm{m}^{-2} \mathrm{~s}^{-1}$ also at $1000 \mathrm{~h}$ under high VPD conditions (Fig. 2c,d). Under high VPD conditions, however, there was a precipitous decline in $g_{s}$ after $1600 \mathrm{~h}$ down to similar values observed under low VPD conditions by late day $(2000 \mathrm{~h})$. Within a two hour window, between $1600 \mathrm{~h}$ and $1800 \mathrm{~h}$, Shiraz $g_{s}$ values dropped by an average of $49 \%$ or $110 \mathrm{mmol} \mathrm{H}_{2} \mathrm{O} \mathrm{m}^{-2} \mathrm{~s}^{-1}$.

In Cabernet Sauvignon, $g_{s}$ values increased steadily from morning until around $1400 \mathrm{~h}$ (max. $g_{s} \sim 200$ mmol $\mathrm{H}_{2} \mathrm{O} \mathrm{m}^{-2} \mathrm{~s}^{-1}$ ) under low VPD conditions (Fig. 2i), decreasing rapidly to similar values as those observed in Shiraz under the same conditions. In contrast with Shiraz under high VPD conditions, Cabernet had lower $g_{s}$ early in the day until around $1400 \mathrm{~h}$, after which a steady decrease was observed; $g_{s}$ values late in the day matched those under low VPD conditions as well as Shiraz under both environmental conditions.

\section{Dynamics of soil-plant-environment interactions}

Diurnal patterns of environmental conditions, soil moisture, and vine water status were studied over a period of eight days between January 19 and January 26, 2021. This period encompassed a range of environmental conditions including hot and cool days (with corresponding high and low VPDs), and irrigation and precipitation events. There was an increasing temperature and VPD trend during the first three days of this period, followed by a decrease on January $22^{\text {nd }}$ leading to the highest VPD values observed on January $24^{\text {th }}$ (daily max. VPD $\sim 6.7 \mathrm{kPa}$ ). Over this period, approx. $20 \mathrm{~mm}$ of irrigation was applied in the Cabernet block and $8 \mathrm{~mm}$ in the Shiraz block, in addition to the nearly $10 \mathrm{~mm}$ of precipitation received in the region on January $25^{\text {th }}$ (Fig. 3a). Changes in soil moisture reflected these events; VWC values in the Cabernet block increased between $10-14 \%$ with $7.6 \mathrm{~mm}$ of irrigation and less than $5 \%$ with the extra rainfall of $10 \mathrm{~mm}$ (Fig. $3 \mathrm{~b}$ ). The same rain event resulted in the soil moisture increasing by approx. $12 \%$ in the Shiraz block with the same soil type. 
Trunk water potentials ( $\left.\Psi_{\text {trunk }}\right)$, as measured continuously by the microtensiometers, were a composite reflection of both soil moisture and environmental conditions, in particular VPD. Patterns of diurnal oscillations of $\Psi_{\text {trunk }}$ were entrained with those of VPD albeit with time offsets on specific days (reported below; Fig. 3a,c). The daily maximum values of $\Psi_{\text {trunk }}$ were usually observed between $0700-0900 \mathrm{~h}$, approx. 2-3 hours after sunrise, and ranged from -0.01 to $-0.10 \mathrm{MPa}$ for Cabernet Sauvignon, and -0.01 and $-0.6 \mathrm{MPa}$ for Shiraz over the observation period (Fig. 3c). The daily minimum values of $\Psi_{\text {trunk }}$ were usually observed between $1620-1820 \mathrm{~h}$, and values ranged between -0.12 and $-0.59 \mathrm{MPa}$ for Cabernet, and -0.67 and $-1.99 \mathrm{MPa}$ for Shiraz.

During the first three days (of the eight-day observation period), the increasing trend of daily maximum VPD from $1.86 \mathrm{kPa}$ on January $19^{\text {th }}$ to $4.21 \mathrm{kPa}$ on January $21^{\text {st }}$ resulted in a concomitant decline in daily minimum $\Psi_{\text {trunk }}$ from -0.42 to $-0.59 \mathrm{MPa}$ (on Jan-20) in Cabernet Sauvignon, and -1.14 to $-1.55 \mathrm{MPa}$ in Shiraz (on Jan-24). Soil moisture levels did not vary for Shiraz during this period, while Cabernet vines received $7.6 \mathrm{~mm}$ of irrigation on January $20^{\text {th }}$ that resulted in an increase of VWC from $22 \%$ to $36 \%$ (Fig. 3b). This irrigation event resulted in an increase of minimum $\Psi_{\text {trunk }}$ in Cabernet on January 20-21 from -0.59 MPa to -0.43 MPa despite higher VPD levels on January 21. The $\Psi_{\text {trunk }}$ responses of both cultivars to these conditions mirrored those of VPD; higher VPD values resulted in lower $\Psi_{\text {trunk. }}$ Shiraz $\Psi_{\text {trunk }}$ appeared to be strongly coupled to VPD; Pearson correlation coefficients $(R)$ were highly correlated with daily minimum $\Psi_{\text {trunk }}$ and $\Delta \Psi_{\text {trunk }}$ (=max. $\Psi_{\text {trunk }}$ - min. $\Psi_{\text {trunk }}$ ), whereas Cabernet was only weakly correlated for the $\Delta \Psi_{\text {trunk }}$ parameter (Table 1).

Table 1. Pearson correlation coefficients $(R)$ of daily maximum VPD vs. minimum and maximum $\Psi_{\text {trunk }}$ values, and diurnal $\Psi_{\text {trunk }}$ differences $\left(\Delta \Psi_{\text {trunk }}=\max . \Psi_{\text {trunk }}-\min . \Psi_{\text {trunk }}\right)$ during the eight day observation period from January 19-26, 2021 for Shiraz and Cabernet Sauvignon. $n=8$.

\begin{tabular}{|l|l|l|l|l|l|l|}
\hline & \multicolumn{4}{|l|}{ Cabernet Sauvignon } & \multicolumn{2}{l|}{ Shiraz } \\
\hline Parameter & Max. $\Psi_{\text {trunk }}$ & Min. $\Psi_{\text {trunk }}$ & $\Delta \Psi_{\text {trunk }}$ & Max. $\Psi_{\text {trunk }}$ & Min. $\Psi_{\text {trunk }}$ & $\Delta \Psi_{\text {trunk }}$ \\
\hline Pearson $R$ & -0.10 & -0.60 & -0.70 & -0.35 & -0.94 & -0.96 \\
\hline$P$-value & 0.811 & 0.115 & 0.053 & 0.393 & 0.001 & 0.000 \\
\hline
\end{tabular}

In the next period of three days, two warm-to-hot days were experienced between January 23-24 with maximum VPD values of 3.84 and $6.70 \mathrm{kPa}$, respectively. On the warmest of these days, January 24 , minimum $\Psi_{\text {trunk }}$ values dropped to -0.51 and $-1.99 \mathrm{MPa}$ in Cabernet and Shiraz, respectively. Irrigation applied in these blocks between January 23-24 resulted in higher maximum $\Psi_{\text {trunk }}$ values, particularly in Shiraz, increasing from -0.60 to $-0.40 \mathrm{MPa}$. On the same warm day (January 24), the diurnal decline in $\Psi_{\text {trunk }}$ in Cabernet was approx. 0.5 MPa while in Shiraz the decline was approx. 1.6 MPa (Fig. 3c). On this warm day, $\Psi_{\text {trunk }}$ continued to drop until around $1720 \mathrm{~h}$ in Cabernet and until around $1820 \mathrm{~h}$ in Shiraz (Note: the highest VPD value was observed around $1730 \mathrm{~h}$ ). In comparison, on cooler (low VPD) 
days, minimum $\Psi_{\text {trunk }}$ values were typically observed around $1620 \mathrm{~h}$ and $1740 \mathrm{~h}$ for Cabernet and Shiraz, respectively. On these cooler days, the highest VPD is typically reached around $1600 \mathrm{~h}$, close to the time of minimum $\Psi_{\text {trunk }}$ of Cabernet, but one hour earlier than that of Shiraz, similar to the observation on the high VPD day. On cooler days with max. VPD $<2.0 \mathrm{kPa}$, diurnal changes in $\Psi_{\text {trunk }}$ averaged 0.2 MPa for Cabernet, and 0.7 MPa for Shiraz. A marked improvement in vine water status (increase in $\Psi_{\text {trunk }}$ ) was observed from January $25^{\text {th }}$ onward resulting from both increases in soil moisture (via irrigation and precipitation), and probably more significantly, decreases in VPD. By the end of the observation period, January 26 , minimum $\Psi_{\text {trunk }}$ values had risen to -0.12 and $-0.67 \mathrm{MPa}$ in Cabernet and Shiraz, respectively.

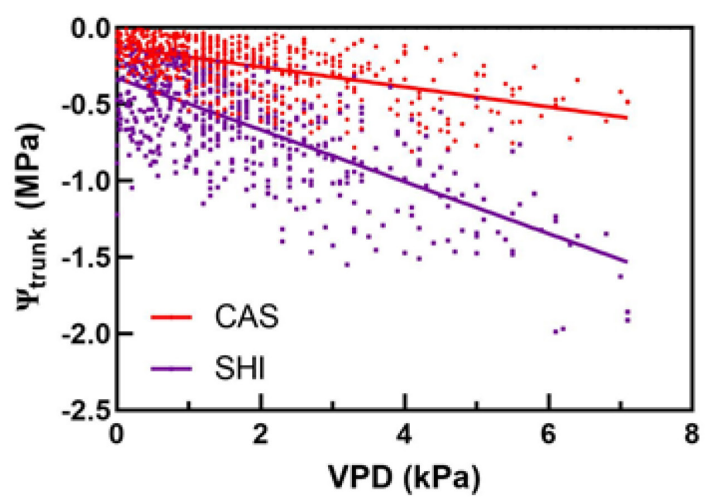

Figure 4: Linear regression analysis of VPD vs $\Psi_{\text {trunk }}$ of Shiraz and Cabernet Sauvignon grapevines over the measurement period. Regression equations: Shiraz: $\Psi_{\text {trunk }}=-0.3272-0.1696 * V P D, R^{2}=0.51$; Cabernet Sauvignon: $\Psi_{\text {trunk }}=-0.1247-$ $0.065 * \mathrm{VPD}, \mathrm{R}^{2}=0.33$. $P$-value for differences between slopes: $<0.001$.

The relationships between VPD and $\Psi_{\text {trunk }}$ for Cabernet and Shiraz for the period December 14, 2020 to February 10, 2021 (0600-2000 h) are presented in Fig. 4. There was a significant difference between cultivars in the sensitivity of vine water status to VPD (as indicated by the slopes of the regression lines) during the two-month peak summer period. Shiraz was more sensitive than Cabernet to changes in atmospheric conditions, dropping its $\Psi_{\text {trunk }}$ by approx. $0.17 \mathrm{MPa} \mathrm{kPa}^{-1}$. In comparison, Cabernet reduced its $\Psi_{\text {trunk }}$ by approx. $0.07 \mathrm{MPa} \mathrm{kPa}^{-1}$.

Time-lagged cross correlation analysis (TLCC) was used to analyse the time series datasets of VPD and $\Psi_{\text {trunk }}$ across two days with contrasting environmental conditions or VPDs: January 26, 2021 (low VPD day; daily max. VPD 1.6 kPa) and February 17, 2021 (high VPD day; daily max. VPD 6.7 kPa). On the low VPD day, the diurnal pattern of VPD followed the typical trend increasing from around $0900 \mathrm{~h}$ to its maximum around $1500 \mathrm{~h}$ after which a gradual decline commenced until reaching its minimum around $2000 \mathrm{~h}$ (Fig.5a). 

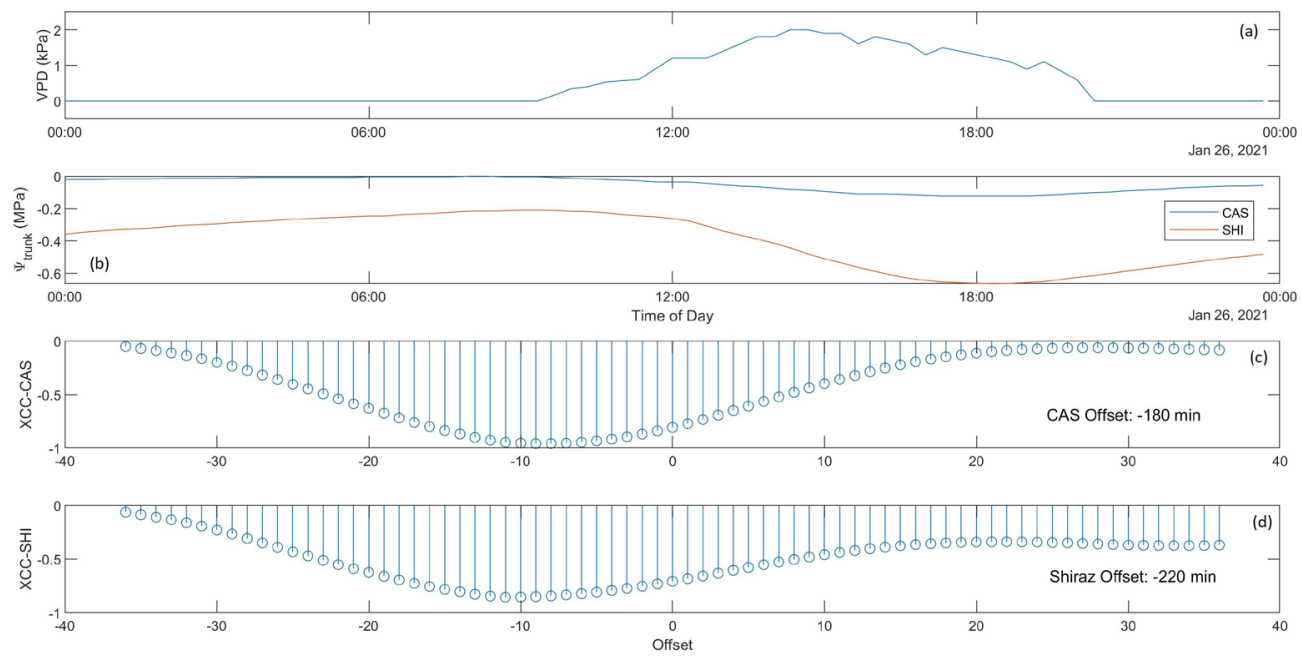

Figure 5: Diurnal plot on a low VPD day (maximum VPD $1.6 \mathrm{kPa}$ ) of (a) VPD, (b) $\Psi_{\text {trunk }}$ for Shiraz and Cabernet Sauvignon, and Pearson Product Moment (cross correlation) coefficient values for Cabernet (c) and Shiraz (d) showing leading or lagging of $\Psi_{\text {trunk }}$ in response to changing VPD.

$\Psi_{\text {trunk }}$ followed a similar but mirrored trend, increasing in the early hours of the day, then decreasing from around noon to its minimum value of around $1800 \mathrm{~h}$ before rising again (Fig. 5b). Cabernet Sauvignon (CAS) and Shiraz appeared to have very similar diurnal patterns of $\Psi_{\text {trunk }}$ despite differences in absolute $\Psi_{\text {trunk }}$ values. TLCC analysis between VPD and $\Psi_{\text {trunk }}$ revealed that CAS had the minimum Pearson Product Moment (normalised cross correlation) coefficient (XCC) at an offset of -9 units or $180 \mathrm{~min}$ (each offset unit $=20 \mathrm{~min}$ ), indicating that $\Psi_{\text {trunk }}$ lagged VPD by $180 \mathrm{~min}$ (Fig. 5c). Similarly, Shiraz $\Psi_{\text {trunk }}$ lagged VPD by 220 min (Fig. 5d).
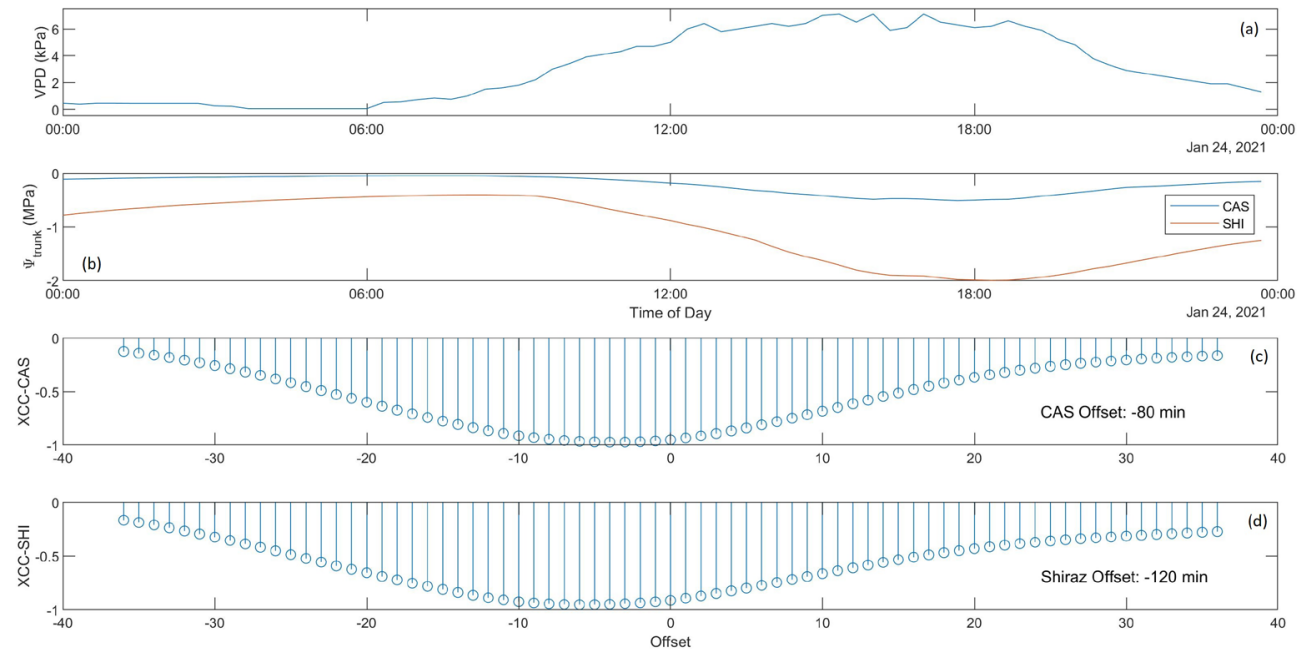

Figure 6: Diurnal plot on a high VPD day (maximum VPD 6.7 kPa) of (a) VPD, (b) $\Psi_{\text {trunk }}$ for Shiraz and Cabernet Sauvignon, and Pearson Product Moment (cross correlation) coefficient values for Cabernet (c) and Shiraz (d) showing leading or lagging of $\Psi_{\text {trunk }}$ in response to changing VPD.

336 On the high VPD day of January 24, the maximum VPD of the day of approx. $6.7 \mathrm{kPa}$ was reached around $1700 \mathrm{~h}$ (Fig. 6a), while the minimum $\Psi_{\text {trunk }}$ in both Shiraz and CAS were much lower than those on the low VPD day, reached around $1800 \mathrm{~h}$ (Fig. 6b). TLCC analysis revealed that CAS $\Psi_{\text {trunk }}$ lagged 
VPD by 80 min (Fig. 6c) while Shiraz $\Psi_{\text {trunk }}$ lagged VPD by 120 min (Fig. 6d), both lower than the time lags observed on the low VPD day.

\section{Discussion}

Microtensiometers (MT) provide a rapid and continuous in situ measurement of water potential in virtually any matrix, and in our context, in woody grapevine trunks. In situ measurements of plant water potential provide valuable estimates of their water status, which are critical for determining irrigation schedules, i.e. when and how much water to apply, for irrigated crops. Although a number of other plant-based sensors currently exist, only very few measure water potential continuously, and those can be challenging to install and unsuitable for long term measurements in the field. MTs overcome some of these limitations due to their small form factor thereby allowing them to be embedded within the woody structures of the plant. This location minimises the risk of damage to the sensing elements from farm machinery, as well as environmental and biotic factors. This first report on the field testing of MTs in mature grapevine trunks under varying environmental conditions provides valuable data of $\Psi_{\text {trunk }}$ on their performance in comparison to traditional methods of water potential measurement, e.g. leaf pressure chamber. To the best of our knowledge, this is the first report of field testing results of MTs. To date, the only other reports of continuous in situ water potentials are reported using stem psychrometers (Dixon and Tyree, 1984; McBurney and Costigan, 1984; Tran et al., 2014) and an osmometric sensor (Meron et al., 2015).

\section{Diurnal patterns of vine water status}

Plant water potential reflects the dynamic interplay between incident solar radiation, VPD, and soil moisture availability, as well as several internal factors within the plant that regulate water transport from the roots to leaves. In the present study, diurnal measurements of leaf, stem and, for the first time, trunk water potentials were conducted on several days characterised by contrasting environmental conditions with low $(<2.0 \mathrm{kPa}$ ) and high ( $>6 \mathrm{kPa}$ ) VPDs (Fig. 2). During this time, soil moisture content (volumetric water content), as measured by a capacitance sensor, varied two-fold from approx. $18 \%$ to $36 \%$ in a well-drained soil. Previous studies documenting diurnal patterns of leaf water potential ( $\Psi_{\text {leaf }}$ ) showed similar trends to the present study; a hyperbolic or U-shaped curve is typically observed with the highest values in the early hours of the day and lowest values in the afternoon in grapevine (Smart, 1974; van Zyl, 1987) and other woody horticultural crops (Klepper, 1968; Olsson and Milthorpe, 1983; Smart and Barrs, 1973). In Vitis vinifera cv. Colombar (grafted onto $99 \mathrm{R}$ rootstock), sunlit leaves had lower $\Psi_{\text {leaf }}$ compared to shaded leaves, and the former reached the lowest $\Psi_{\text {leaf }}$ earlier in the day ( $1200 \mathrm{~h}$ for sunlit compared to $1400 \mathrm{~h}$ for shaded), but only when there was a deficit in soil moisture (van Zyl, 1987). In California, Williams and Baeza (2007) observed in several red grape cultivars that the lowest $\Psi_{\text {leaf }}$ was reached around $1600 \mathrm{~h}$ when the vines were either well-watered, receiving irrigation equal or higher than full replacement (100\%) of crop evapotranspiration $\left(E T_{c}\right)$, or deficit irrigated at $40 \% E T_{c}$. In comparison, Thompson Seedless reached its lowest $\Psi_{\text {leaf }}$ by around $1300 \mathrm{~h}$ when well-watered and by $1000 \mathrm{~h}$ under non-irrigated conditions. The Williams and Baeza study unfortunately did not report on the early morning or late day recovery patterns in $\Psi_{\text {leaf }}$ of these vines so difficult to compare with the current study. In Tempranillo grapevines receiving $70 \% \mathrm{ET}_{\mathrm{c}}, \Psi_{\text {leaf }}$ and $\Psi_{\text {stem }}$ were observed to be at their lowest values around $1400 \mathrm{~h}$ and at a similar time to the highest VPD of the day (Cole and Pagay, 2015), corroborating with observations in the present study.

Freeman et al. (1982) found in Chardonnay and Carignan that the lowest $\Psi_{\text {leaf }}$ was reached between $1500 \mathrm{~h}-1600 \mathrm{~h}$ in Davis, California conditions. In the Chasselas cultivar in Switzerland, Zufferey and 
co-workers found that the diurnal patterns of $\Psi_{\text {stem }}$ showed a similar U-shaped pattern, and reached a minimum value around $1430 \mathrm{~h}$ on a high VPD day $(\sim 3.0 \mathrm{kPa})$ independent of soil moisture and at the same time on a low VPD day ( $1.5 \mathrm{kPa}$ ) in irrigated vines (Zufferey et al., 2011). However, on a low VPD day without irrigation, the vines reached their minimum $\Psi_{\text {stem }}$ values only around $1600 \mathrm{~h}$ likely due to the low transpiration rates. The effect of soil moisture on diurnal $\Psi_{\text {leaf }}$ patterns is quite marked; irrigation of Shiraz in a warm climate resulted in the highest transpiration rates and lowest $\Psi_{\text {leaf }}$ around $1200 \mathrm{~h}$ and $1500 \mathrm{~h}$, respectively (Smart, 1974). In comparison, water-stressed vines reached their lowest $\Psi_{\text {leaf }}$ also around $1500 \mathrm{~h}$, but the highest transpiration rates were reached around $1100 \mathrm{~h}$. Our diurnal observations indicated that the lowest $\Psi_{\text {leaf }}, \Psi_{\text {stem }}$, and $\Psi_{\text {trunk }}$ were reached around $1400 \mathrm{~h}, 1600 \mathrm{~h}$ and $1800 \mathrm{~h}$, respectively, on low VPD days, whereas these times were advanced on the

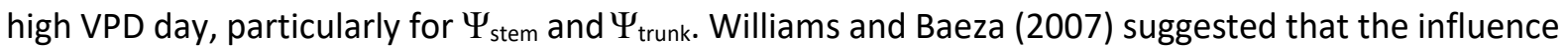
of VPD on $\Psi_{\text {leaf }}$ decreases as soil moisture decreases.

Modeling of diurnal patterns of $\Psi_{\text {leaf }}$ predicted that the lowest values are likely to be reached around $1400 \mathrm{~h}$, approx. two hours after the highest leaf transpiration rates are reached (Katerji et al. 1986). This transient (or delay) in $\Psi_{\text {stem }}$ response can be attributed to the contributions of both plant tissue water ( 13\%) and root uptake of soil moisture ( 87\%) to the transpiration stream. These modelled patterns compare favourably with those obtained from lysimeters; maximum transpiration rates were reached between $1200 \mathrm{~h}$ and $1400 \mathrm{~h}$ (Williams et al., 2012). The same study found that higher vine sizes or crop factors result in not only increased transpiration rates, as expected, but also a delayed peak by as much as two hours. Similar patterns of vine transpiration were observed in studies using sap flow and thermal dissipation sensors (Braun and Schmid, 1999; Pagay and Skinner, 2018). The diurnal measurements of leaf stomatal conductance $\left(g_{s}\right)$ in the present study indicated that the highest values were reached in the afternoon on low VPD days and late morning on high VPD days. Reductions in $g_{s}$ following this peak resulted in increases in $\Psi_{\text {leaf }}$ and $\Psi_{\text {stem, but not }} \Psi_{\text {trunk. }}$. This lack of response from $\Psi_{\text {trunk }}$ might indicate a level of buffering of water potential in the woody organs of the plant, in this case the trunk, where xylem vessels are surrounded by parenchymal cells that can contribute water to the transpiration stream, the so-called 'capacitance effect' (Salomón et al., 2017; Waring and Running, 1978).

Environmental conditions played a key role in determining patterns and values of $\Psi_{\text {w; }}$ both $\Psi_{\text {leaf }}$ and $\Psi_{\text {stem }}$ were strongly influenced by VPD. Consistent with other studies, our study found a strong negative relationship between $\Psi_{\text {trunk }}$ and VPD (Fig. 4). In California, across three cultivars, Williams and Baeza (2007) found that the slope of the VPD- $\Psi_{\text {leaf }}$ relationship was $0.079 \mathrm{MPa} \mathrm{kPa}^{-1}$ while for the VPD- $\Psi_{\text {stem }}$ relationship was $0.068 \mathrm{MPa} \mathrm{kPa}^{-1}$. In comparison, our study found slopes for VPD- $\Psi_{\text {trunk }}$ in Cabernet Sauvignon to be $0.07 \mathrm{MPa} \mathrm{kPa}^{-1}$ while for Shiraz this slope was higher at $0.17 \mathrm{MPa} \mathrm{kPa}^{-1}$. The higher sensitivity of Shiraz grapevines to VPD might reflect its relatively anisohydric behaviour that has been previously reported (Dayer et al., 2020; Schultz, 2003), with a weaker regulation of stomatal conductance $\left(g_{s}\right)$ under either declining soil moisture or increasing VPD. In contrast, Cabernet Sauvignon's lower $\Psi_{\text {trunk }}$ sensitivity to VPD suggests a tighter coupling to the environment - both soil moisture and VPD.

\section{Temporal coupling of plant water status and atmosphere}

Continuous measurements of plant water status provide a valuable dataset for the analysis of its temporal patterns as well as relationships with the environment, both soil and plant. Our characterisation of the dynamic nature of $\Psi_{\text {trunk }}$ in Shiraz and Cabernet Sauvignon grapevines using MTs was done both inter- and intra-day (diurnally). Furthermore, using a time-lagged cross correlation statistical approach, we conducted a detailed temporal analysis of the interrelationships between VPD 
and $\Psi_{\text {trunk }}$ that revealed the differences between the two grapevine cultivars in their response to different environmental conditions. Cross-correlation analysis has been used for signal processing and pattern recognition in diverse fields including spectroscopy, seismology, finance, and quantum information processing (Podobnik and Stanley, 2008). In plants, the response of water potential to the environment has been characterised previously, but comparisons of different cultivars using in situ measurements of $\Psi_{w}$ have not been reported hitherto. The slower transient or response of $\Psi_{\text {trunk }}$ to changes in VPD over the course of a day in Shiraz compared to Cabernet (Fig. 5) may reflect its greater capacity for root water uptake and/or increased capacitance from the parenchymal cells surrounding xylem vessels. Although not specifically measured in this study, it is likely that the Shiraz vines had bigger root systems (biomass) than Cabernet based on the visually larger canopies and higher leaf area index (LAI) values (Shiraz LAI 7.4; Cabernet LAI 5.6; average LAI data obtained from an accompanying study on 32 vines per cultivar).

Under environmentally demanding (high VPD) conditions, the $\Psi_{\text {trunk }}$ of both cultivars were more strongly coupled to VPD with shorter transients. The more rapid vine response under high VPD conditions may result from higher transpiration rates and more open stomata, which allowed the $\Psi_{\text {trunk }}$ in Shiraz to drop to nearly -2 MPa compared to -0.6 MPa on the low VPD day. In comparison, the relatively modest reduction of Cabernet $\Psi_{\text {trunk }}$ of $\sim 0.4 \mathrm{MPa}$ when the VPD increased may indicate near-isohydric behaviour. This observation is consistent with other reports of the stomatal behaviour of Cabernet Sauvignon (Collins and Loveys, 2010), but in contrast to other reports that Cabernet Sauvignon has anisohydric behaviour (Suter et al., 2019).

The stem potential sensor based on osmometry tested in tangerine trees in Israel provided diurnal $\Psi_{\text {stem }}$ values that correlated temporally with trunk temperature and evapotranspiration (ET), showing a stem water potential lag of approx. five hours with both parameters (Meron et al., 2015). The same sensor used in peach trees showed a lag of five hours with destructive, pressure chamber measurements of $\Psi_{\text {stem }}$ and a similar (ca. five hour) lag from ET. Our results indicate that the time lag of $\Psi_{\text {trunk }}$ was cultivar- and VPD-dependent; in the order of 3-4 hours on a low VPD day and 1-2 hours on a high VPD day with Cabernet at the low end of these ranges.

\section{Measurement of predawn water potential and its timing}

The predawn water potential $\left(\Psi_{\mathrm{pd}}\right)$ is considered a reliable indicator of root xylem pressure potential $\left(\Psi_{\mathrm{p}}\right)$ or soil matric potential $\left(\Psi_{\mathrm{m}}\right)$ based on the equilibration of $\Psi_{\mathrm{w}}$ between the plant and soil when the canopy transpiration rate $(E)$ is zero or negligible (Ameglio et al., 1999; Jones, 2007). The $\Psi_{\text {pd }}$ is influenced by soil water content and distribution, root area/distribution, and soil and root hydraulic conductivities (Garcia-Tejera et al., 2021). It should be noted that $\Psi_{\mathrm{pd}}$ is not a reflection of the average soil $\Psi_{\mathrm{w}}$ across the rhizosphere, but rather the $\Psi_{\mathrm{w}}$ of its wettest portion (Pagay et al., 2016; Schmidhalter, 1997). Furthermore, Ameglio et al. (1999) reported that $\Psi_{\text {pd }}$ may not reflect plant $\Psi_{w}$ and hence has limited application for irrigation scheduling of crops. On a diurnal basis, our observation that the maximum $\Psi_{w}$ in the plant (based on $\Psi_{\text {trunk }}$ ), widely accepted as the $\Psi_{\text {pd }}$ (Boyer, 1995), occurred around 0700-0800 h, 2-3 hours after sunrise and that reported in the literature (Chone et al., 2001; Correia et al., 1995; Williams and Araujo, 2002). The fundamental requirement for the equilibration of plant and soil $\Psi_{w}$ is that (nocturnal) transpiration is zero or near zero, which is sometimes not the case in well-watered crops in warm-to-hot climates (Pagay, 2016). Previous studies characterising diurnal canopy $E$ showed that $E$ reaches its minimum value (zero or near-zero) around $0100 \mathrm{~h}$ under low VPD conditions and around $0600 \mathrm{~h}$ under high VPD conditions, under well-watered conditions (Pagay, 2016). Using sap flow sensors in grapevines, Braun and Schmid (1999) observed that the minimum canopy $E$ for the day was reached around $2100 \mathrm{~h}$, and $E$ did not start increasing until approx. 
$0900 \mathrm{~h}$, several hours after dawn, the next day. Differences between the times of minimum $E$ and highest $\Psi_{w}$ diurnally may be the result of hydraulic resistances in the soil-plant continuum, which are influenced by soil type, soil moisture, ambient VPD, and root biomass and distribution (Garcia-Tejera et al., 2021; Sato et al., 2006). Our observations of maximum plant $\Psi_{\mathrm{w}}$ being reached in the early morning, between 0700-0800 h, are consistent with another study reporting that $\Psi_{\text {stem }}$ does not start decreasing from its maximum diurnal value until the early morning, approx. $0700 \mathrm{~h}$ (Cole and Pagay, 2015), but in contrast to another report that $\Psi_{\text {pd }}$ decreases from $0330 \mathrm{~h}$ (Carbonneau et al., 2004). The observation has implications for the timing of measurement of $\Psi_{\mathrm{pd}}$, if used as a metric for crop irrigation scheduling as recommended previously (Stricevic and Caki, 1997). Donovan et al. (2001) found that $\Psi_{\mathrm{pd}}$ and $\Psi_{\mathrm{p}}$ in several woody plants may not reflect $\Psi_{\mathrm{m}}$ even under well-watered conditions without nocturnal transpiration. This was hypothesized to be due to the accumulation of high concentrations of solutes in the leaves, although grapevines have only modest levels of osmotic adjustment compared to many other woody horticultural crops (Rodrigues et al., 1993).

\section{Which plant water potential metric to use for irrigation scheduling?}

MTs offer yet another plant water status metric, $\Psi_{\text {trunk, }}$ that has been shown in this study to have a different range of values compared to conventional measures of $\Psi_{\text {leaf }}$ and $\Psi_{\text {stem. These conventional }}$ metrics have been well characterised for irrigation scheduling and thresholds have been suggested in the literature (Deloire and Heyns, 2011; Romero et al., 2010).

i. Leaf water potential

The $\Psi_{\text {leaf }}$ is a convenient measurement with the use of a leaf pressure chamber, although time and labour intensive. The inherent variability of leaves in a plant (and even within a shoot or branch) make this metric highly variable in its value (McCutchan and Shackel, 1992). Jones (1990) suggested that $\Psi_{\text {leaf }}$ may be an erroneous indicator of plant water status as $\Psi_{\text {leaf }}$ homeostasis may occur under different soil moisture and environmental conditions. This homeostasis in $\Psi_{\text {leaf }}$ is exemplified no better than in plants that lie at the opposite ends of the isohydric-anisohydric spectrum. Tardieu and Simonneau (1998) found that in sunflower and barley, characterised as anisohydric where there is weak coupling between soil moisture and stomatal conductance $\left(g_{s}\right), \Psi_{\text {leaf }}$ declined in relation to VPD and soil moisture. In contrast, maize, characterised as near-isohydric, where stomatal closure occurs with declining soil moisture, $\Psi_{\text {leaf }}$ was virtually unchanged under declining soil moisture until near death. Grapevines cultivars also have been shown to vary in their homeostasis in $\Psi_{\text {leaf }}$ under declining soil moisture. For example, Syrah (syn. Shiraz) was shown to be relatively anisohydric compared to Grenache, which was near-isohydric (Schultz, 2003). The differential response between cultivars is thought to be related to leaf and xylem abscisic acid and hydraulic regulation (Dayer et al., 2020). Based on these physiological responses, the use of $\Psi_{\text {leaf }}$ for irrigation scheduling of relatively isohydric plants may underestimate their true water stress and therefore irrigation requirements potentially leading to a vicious cycle.

\section{ii. Stem water potential}

The $\Psi_{\text {stem }}$ overcomes some of the liabilities associated with $\Psi_{\text {leaf, }}$ particularly that of leaf-level variability with a shoot or branch, as it integrates all the leaves of that shoot/branch, and is therefore less variable than $\Psi_{\text {leaf }}$ (Williams and Araujo, 2002). The $\Psi_{\text {stem }}$ was also shown to be a more sensitive indicator of plant water status than $\Psi_{\text {leaf }}$ (Garnier and Berger, 1985) and could reliably discriminate soil moisture deficits (Chone et al., 2001) earlier than both $\Psi_{\text {leaf }}$ and $\Psi_{\text {pd }}$ (Selles and Berger, 1990). Despite these advantages, from a practical standpoint, $\Psi_{\text {stem }}$ is somewhat more involved, requiring leaves to be enclosed in opaque bags to stop transpiration and allow $\Psi_{\text {leaf }}$ and $\Psi_{\text {stem }}$ to equilibrate; this needs to be done at least one hour prior to measurement in the pressure chamber (Chone et al., 
518 2001). This delayed measurement is not amenable to rapid measurements or automation, which

519 applies to $\Psi_{\text {leaf }}$ also.

520 iii. Trunk water potential

521 The $\Psi_{\text {trunk }}$ is arguably the most stable of these three metrics, integrating all the leaves of the plant in

522 a stable tissue that is relatively unaffected by external factors as are $\Psi_{\text {leaf }}$ and $\Psi_{\text {stem. }}$. Our measurements

523 of these three vine $\Psi_{\mathrm{w}}$ metrics indicated that, in some instances, $\Psi_{\text {trunk }}$ tended to be nearly $1 \mathrm{MPa}$

524 higher than $\Psi_{\text {leaf, }}$ indicative of the high hydraulic resistances between the trunk and leaves. Previous

525 reports have shown that the highest hydraulic resistance in this pathway lies in the leaf, representing

526 as much as 30\% of the overall resistance in the plant (Sack et al., 2003), likely due to the fewer and

527 narrower xylem vessels in this section of the pathway compared to distal sections. The $\Psi_{\text {trunk }}$ was also

528 susceptible to the least fluctuations diurnally, although this was only shown to be true under low VPD

529 conditions (Fig. 2). Its central location in the plant between the roots and leaves, as well as buffering

530 of xylem water status (pressure potential) via capacitance from adjoining parenchymal cells and

531 secondary xylem (Meinzer et al., 2009) would be plausible reasons for the stability of the trunk's water

532 status. However, we observed that $\Psi_{\text {trunk }}$ responded to changes in soil moisture (via irrigations) less

533 rapidly than to changes in VPD (Fig. 3), which suggests that the trunk may be well-coupled to the

534 leaves despite the high hydraulic resistances in the leaf petioles. A related and somewhat surprising

535 observation was made under high VPD conditions: we consistently observed the crossing over of the

$536 \Psi_{\text {trunk }}$ and $\Psi_{\text {stem }}$ lines in the mid-afternoon (Fig. 2e,k). The lower $\Psi_{\text {trunk }}$ value (compared to $\Psi_{\text {stem }}$ ) during

537 warm afternoons indicates that the trunks of both cultivars were under considerably more water

538 stressed than the stems and similar to the leaves late in the afternoon. A plausible explanation for this

539 response is that the roots may be under water stress owing to transient water deficits at the soil-root

540 interface due to high transpiration rates under high VPD conditions. Pagay et al. (2016) reported that,

541 under high VPD conditions, low plant water potentials could result, if the capillary conductivity of soils

542 in the rhizosphere is inadequate to support high canopy transpiration rates.

543 Continuous measurements of $\Psi_{\text {trunk }}$ using in situ microtensiometers, which were demonstrated in

544 field-grown plants for the first time in this study, offers a convenient measurement of plant water

545 status for irrigation scheduling. Furthermore, these in situ measurements of plant water potential

546 provide a powerful tool for physiological studies of plant hydraulics in a dynamic environment, for

547 example, studies on the limiting water potentials of plants as well as those involving cavitation and

548 embolism recovery dynamics. Microtensiometers are also amenable to automation, for example to

549 automate irrigation scheduling via a decision support system in which thresholds of $\Psi_{\text {trunk }}$ are pre-

550 programmed in irrigation controllers for various crop phenological stages and that also incorporate

551 other relevant environmental parameters such as weather forecast and soil moisture data for

552 precision irrigation. The use of published $\Psi_{\text {stem }}$ or $\Psi_{\text {leaf }}$ thresholds to drive irrigation decisions should

553 be based on measurements of the specific metric for which the threshold has been developed; a

554 translation of those values to $\Psi_{\text {trunk }}$ would not be appropriate due to physiological, hydraulic and

555 anatomical differences between plants.

\section{Data availability statement}

557 The data supporting the findings of this study are available upon request from the author.

\section{Acknowledgements}

559 The author thanks the following individuals for assistance with the project: Dr Franziska Doerflinger 560 (Plant and Food Research Australia), Dr Michael Santiago (FloraPulse), Mr Popolopoulos, Felipe 
561 Canela, and Rochelle Schlank. The project was supported by funding from Wine Australia (project: UA

562 1803-1.3), and in-kind support by Katnook Estate and Wynns Coonawarra Estate.

563

564

565

566

567

568

569

570

571

572

573

574

575

576

577

578

579

580

581

582

583

584

585

586

587

588

589

590

591

592

593

594

595

596

597

598

599

600

601

602

\section{References}

Ameglio T, Archer P, Cohen M, Valancogne C, Daudet FA, Dayau S, Cruiziat P. 1999. Significance and limits in the use of predawn leaf water potential for tree irrigation. Plant and Soil 207, 155-167.

Black WL, Santiago M, Zhu SY, Stroock AD. 2020. Ex situ and in situ measurement of water activity with a MEMS tensiometer. Analytical Chemistry 92, 716-723.

Boyer JS. 1995. Measuring the water status of plants and soils: Academic Press.

Braun P, Schmid J. 1999. Sap flow measurements in grapevines (Vitis vinifera L.) - 1. Stem morphology and use of the heat balance method. Plant and Soil 215, 39-45.

Bureau_of_Meteorology.

2021.

http://www.bom.gov.au/climate/averages/tables/cw_026091.shtml. Date accessed: 03/04/2021.

Carbonneau A, Deloire A, Costanza P. 2004. Leaf water potential meaning of different modalities of measurements. Journal International Des Sciences De La Vigne Et Du Vin 38, 15-19.

Chatfield C, Xing H. 2019. The analysis of time series : an introduction with R. Boca Raton: CRC Press, Taylor \& Francis Group.

Cheong JH. 2020. Four ways to quantify synchrony between time series data. https://doi.org/10.17605/OSF.IO/BA3NY. Accessed 15/03/2021.

Chone X, van Leeuwen C, Dubourdieu D, Gaudillere JP. 2001. Stem water potential is a sensitive indicator of grapevine water status. Annals of Botany 87, 477-483.

Cole J, Pagay V. 2015. Usefulness of early morning stem water potential as a sensitive indicator of water status of deficit-irrigated grapevines (Vitis vinifera L.). Scientia Horticulturae 191, 10-14.

Collins M, Loveys B. 2010. Optimising irrigation for different cultivars. Final report to Grape and Wine Research \& Development Corporation. Project Number CSP 05/02.

Corell M, Giron IF, Galindo A, Torrecillas A, Torres-Sanchez R, Perez-Pastor A, Moreno F, Moriana A. 2014. Using band dendrometers in irrigation scheduling Influence of the location inside the tree and comparison with point dendrometer. Agricultural Water Management 142, 29-37.

Cormier J, Depardieu C, Letourneau G, Boily C, Gallichand J, Caron J. 2020. Tensiometer-based irrigation scheduling and water use efficiency of field-grown strawberries. Agronomy Journal 112, 2581-2597.

Correia MJ, Pereira JS, Chaves MM, Rodrigues ML, Pacheco CA. 1995. ABA xylem concentrations determine maximum daily leaf conductance of field-grown Vitis vinifera $L$ plants. Plant Cell and Environment 18, 511-521.

Dayer S, Scharwies JD, Ramesh SA, Sullivan W, Doerflinger FC, Pagay V, Tyerman SD. 2020. Comparing hydraulics between two grapevine cultivars reveals differences in stomatal regulation under water stress and exogenous ABA applications. Frontiers in Plant Science 11.

Deloire A, Heyns D. 2011. The leaf water potentials: principles, method and thresholds. Wineland Magazine technical yearbook, 129-131.

Dixon MA, Tyree MT. 1984. A new stem hygrometer, corrected for temperature gradients and calibrated against the pressure bomb. Plant Cell and Environment 7, 693-697.

Donovan LA, Linton MJ, Richards JH. 2001. Predawn plant water potential does not necessarily equilibrate with soil water potential under well-watered conditions. Oecologia 129, 328-335. 
Freeman BM, Kliewer WM, Stern P. 1982. Influence of windbreaks and climatic region on diurnal fluctuation of leaf water potential, stomatal conductance, and leaf temperature of grapevines. American Journal of Enology and Viticulture 33, 233-236.

Garcia-Tejera O, Lopez-Bernal A, Orgaz F, Testi L, Villalobos FJ. 2021. The pitfalls of water potential for irrigation scheduling. Agricultural Water Management 243.

Garnier E, Berger A. 1985. Testing water potential in peach trees as an indicator of water stress. Journal of Horticultural Science 60, 47-56.

Ginestar C, Eastham J, Gray S, lland P. 1998. Use of sap-flow sensors to schedule vineyard irrigation. I. Effects of post-veraison water deficits on water relations, vine growth, and yield of Shiraz grapevines. American Journal of Enology and Viticulture 49, 413-420.

Jones HG. 1990. Physiological aspects of the control of water status in horticultural crops. Hortscience 25, 19-26.

Jones HG. 1999. Use of infrared thermometry for estimation of stomatal conductance as a possible aid to irrigation scheduling. Agricultural and Forest Meteorology 95, 139-149.

Jones HG. 2007. Monitoring plant and soil water status: established and novel methods revisited and their relevance to studies of drought tolerance. Journal of Experimental Botany 58, 119-130.

Klepper B. 1968. Diurnal pattern of water potential in woody plants. Plant Physiology 43, 1931-1934.

McBurney T, Costigan PA. 1984. Rapid oscillations in plant water potential measured with a stem psychrometer. Annals of Botany 54, 851-853.

McCutchan H, Shackel KA. 1992. Stem water potential as a sensitive indicator of water stress in prune trees (Prunus domestica L cv French). Journal of the American Society for Horticultural Science 117, 607-611.

Meinzer FC, Johnson DM, Lachenbruch B, McCulloh KA, Woodruff DR. 2009. Xylem hydraulic safety margins in woody plants: coordination of stomatal control of xylem tension with hydraulic capacitance. Functional Ecology 23, 922-930.

Meron M, Goldberg SY, Solomon-Halgoa A, Ramon G. 2015. Embedded stem water potential sensor. In: Stafford, ed. Precision agriculture '15: Wageningen Academic Publishers, Wageningen, 527-532.

Michel BE. 1977. Miniature stem thermocouple hygrometer. Plant Physiology 60, 645-647.

Olsson KA, Milthorpe FL. 1983. Diurnal and spatial variation in leaf water potential and leaf conductance of irrigated peach trees. Australian Journal of Plant Physiology 10, 291-298.

Pagay V. 2016. Effects of irrigation regime on canopy water use and dry matter production of 'Tempranillo' grapevines in the semi-arid climate of Southern Oregon, USA. Agricultural Water Management 178, 271-280.

Pagay V, Santiago M, Sessoms DA, Huber EJ, Vincent O, Pharkya A, Corso TN, Lakso AN, Stroock AD. 2014. A microtensiometer capable of measuring water potentials below-10 MPa. Lab on a Chip 14, 2806-2817.

Pagay V, Skinner A. 2018. Continuous in situ measurements of crop water stress in 'Shiraz' grapevines using a thermal diffusivity sensor. In: Herppich WB, ed. International Symposium on Sensing Plant Water Status - Methods and Applications in Horticultural Science, Vol. 1197, 83-88.

Pagay V, Zufferey V, Lakso AN. 2016. The influence of water stress on grapevine (Vitis vinifera L.) shoots in a cool, humid climate: growth, gas exchange and hydraulics. Functional Plant Biology 43, 827-837. 
645 Podobnik B, Stanley HE. 2008. Detrended cross-correlation analysis: A new method for analyzing two 646 nonstationary time series. Physical Review Letters 100.

647 Richards LA. 1942. Soil moisture tensiometer materials and construction. Soil Science 53, 241-248.

648 Rodrigues ML, Chaves MM, Wendler R, David MM, Quick WP, Leegood RC, Stitt M, Pereira JS. 1993. 649 Osmotic adjustment in water-stressed grapevine leaves in relation to carbon assimilation. Australian 650 Journal of Plant Physiology 20, 309-321.

651 Romero P, Fernandez-Fernandez JI, Martinez-Cutillas A. 2010. Physiological thresholds for efficient 652 regulated deficit irrigation management in winegrapes grown under semiarid conditions. American 653 Journal of Enology and Viticulture 61, 300-312.

654 Sack L, Cowan PD, Jaikumar N, Holbrook NM. 2003. The 'hydrology' of leaves: co-ordination of 655 structure and function in temperate woody species. Plant Cell and Environment 26, 1343-1356.

656 Salomón RL, Limousin J-M, Ourcival J-M, Rodríguez-Calcerrada J, Steppe K. 2017. Stem hydraulic 657 capacitance decreases with drought stress: implications for modelling tree hydraulics in the 658 Mediterranean oak Quercus ilex. Plant, Cell \& Environment 40, 1379-1391.

659 Sato T, Abdalla OS, Oweis TY, Sakuratani T. 2006. Effect of supplemental irrigation on leaf stomatal 660 conductance of field-grown wheat in northern Syria. Agricultural Water Management 85, 105-112.

661 Scalisi A, Bresilla K, Grilo F. 2017. Continuous determination of fruit tree water-status by plant-based 662 sensors. Italus Hortus 24, 39-50.

663 Schmidhalter U. 1997. The gradient between pre-dawn rhizoplane and bulk soil matric potentials, and 664 its relation to the pre-dawn root and leaf water potentials of four species. Plant Cell and Environment $66520,953-960$.

666 Scholander PF, Hammel HT, Bradstreet ED, Hemmingsen EA. 1965. Sap pressure in vascular plants negative hydrostatic pressure can be measured in plants. Science 148, 339-346.

668 Schultz HR. 2003. Differences in hydraulic architecture account for near-isohydric and anisohydric 669 behaviour of two field-grown Vitis vinifera L. cultivars during drought. Plant Cell and Environment 26, 670 1393-1405.

Selles G, Berger A. 1990. Physiological indicators of plant water status as criteria for irrigation scheduling. International Symposium on Scheduling of Irrigation for Vegetable Crops under Field Condition, Vols 1 and 2 278, 87-100.

Shackel K. 2011. A plant-based approach to deficit irrigation in trees and vines. Hortscience 46, 173675177.

Smart RE. 1974. Aspects of water relations of grapevine (Vitis vinifera). American Journal of Enology and Viticulture 25, 84-91.

Smart RE, Barrs HD. 1973. Effect of environment and irrigation interval on leaf water potential of 4

680 Stricevic R, Caki E. 1997. Relationships between available soil water and indicators of plant water status of sweet sorghum to be applied in irrigation scheduling. Irrigation Science 18, 17-21.

Suter B, Triolo R, Pernet D, Dai ZW, Van Leeuwen C. 2019. Modeling stem water potential by separating the effects of soil water availability and climatic conditions on water status in grapevine (Vitis vinifera L.). Frontiers in Plant Science 10. 
Tran N, Graham T, Zhang P, Bam P, Black K, Reeves R, Downey A, Dixon M. 2014. Irrigation management strategies for nursery trees based on plant water status measured with automated stem psychrometers. CSPB Conference, CSPB Conference - Irrigation Management Strategies for Nursery Trees. Guelph, Ontario, Canada.

van Zyl JJ. 1987. Diurnal variation in grapevine water stress as a function of changing soil water status and meteorological conditions. South African Journal of Enology and Viticulture 8, 45-52.

694 Waring RH, Running SW. 1978. Sapwood water storage: its contribution to transpiration and effect 695 upon water conductance through the stems of old-growth Douglas-fir. Plant, Cell \& Environment 1, 696 131-140.

697 Williams LE, Araujo FJ. 2002. Correlations among predawn leaf, midday leaf, and midday stem water 698 potential and their correlations with other measures of soil and plant water status in Vitis vinifera. 699 Journal of the American Society for Horticultural Science 127, 448-454.

700 Williams LE, Baeza P. 2007. Relationships among ambient temperature and vapor pressure deficit and leaf and stem water potentials of fully irrigated, field-grown grapevines. American Journal of Enology and Viticulture 58, 173-181.

Williams LE, Baeza P, Vaughn P. 2012. Midday measurements of leaf water potential and stomatal conductance are highly correlated with daily water use of Thompson Seedless grapevines. Irrigation Science 30, 201-212.

Zufferey V, Cochard H, Ameglio T, Spring JL, Viret O. 2011. Diurnal cycles of embolism formation and repair in petioles of grapevine (Vitis vinifera cv. Chasselas). Journal of Experimental Botany 62, 38853894. 